(C) 2018 IEEE. Personal use of this material is permitted. Permission from IEEE must be obtained for all other uses, in any current or future media, including reprinting/republishing this material for advertising or promotional purposes, creating new collective works, for resale or redistribution to servers or lists, or reuse of any copyrighted component of this work in other works. 


\title{
Vegetation Indices Combining the Red and Red-Edge Spectral Information for Leaf Area Index Retrieval
}

\author{
Qiaoyun Xie ${ }^{\circledR}$, Jadu Dash, Wenjiang Huang ${ }^{\circledR}$, Dailiang Peng ${ }^{\circledR}$, Qiming Qin, Hugh Mortimer, Raffaele Casa, \\ Stefano Pignatti, Giovanni Laneve ${ }^{(1)}$, Simone Pascucci, Yingying Dong, and Huichun Ye
}

\begin{abstract}
Leaf area index (LAI) is a crucial biophysical variable for agroecosystems monitoring. Conventional vegetation indices (VIs) based on red and near infrared regions of the electromagnetic spectrum, such as the normalized difference vegetation index (NDVI), are commonly used to estimate the LAI. However, these indices commonly saturate at moderate-to-dense canopies (e.g., NDVI saturates when LAI exceeds three). Modified VIs have then been proposed to replace the typical red/green spectral region with the red-edge spectral region. One significant and often ignored aspect of this modification is that the reflectance in the red-edge spectral region is comparatively sensitive to chlorophyll content which is highly variable between different crops and different phenological states. In this study, three improved indices are proposed combining reflectance both in the red and red-edge spectral regions into the NDVI, the modified simple ratio index (MSR), and the green chlorophyll index $\left(\mathbf{C I}_{\text {green }}\right)$ formula. These improved indices are termed NDVI $_{\text {red \& RE }}$ (red and red-edge NDVI), MSR $_{\text {red \& RE }}$ (red and red-edge MSR index), and $C_{\text {red\& } R E}$ (red and red-edge $C I$ ). The indices were tested using RapidEye images and in-situ data from
\end{abstract}

Manuscript received November 15, 2017; revised February 7, 2018; accepted February 26, 2018. This work was supported in part by the National Key R \& D Program of China under Grant 2016YFB0501501 and Grant 2016YFD0300702; in part by the Youth Innovation Promotion Association Chinese Academy of Sciences under Grant Y4YR1300QM; in part by the National Natural Science Foundation of China (61661136004); and in part by the CNR-CAS scientific cooperation agreement. (Corresponding authors: Wenjiang Huang; Dailiang Peng.)

Q. Xie is with the Climate Change Cluster (C3), University of Technology Sydney, Sydney, N.S.W. 2007, Australia, also with the Department of Geography and Environment, University of Southampton, Southampton SO171BJ, U.K., and also with the Key Laboratory of Digital Earth Science, Institute of Remote Sensing and Digital Earth, Chinese Academy of Sciences, Beijing 100094, China (e-mail: xieqiaoyun2011@gmail.com).

J. Dash is with the Department of Geography and Environment, University of Southampton, Southampton SO171BJ, U.K (e-mail: J.DASH@soton.ac.uk).

W. Huang, D. Peng, Y. Dong, and H. Ye are with the Key Laboratory of Digital Earth Science, Institute of Remote Sensing and Digital Earth, Chinese Academy of Sciences, Beijing 100094, China (e-mail: huangwj@radi.ac.cn; pengdl@radi.ac.cn; dongyy@radi.ac.cn; yehuichun000@126.com).

Q. Qin is with the Institute of Remote Sensing and Geographic Information Systems, Peking University, Beijing 100871, China (e-mail: qmqin@ pku.edu.cn).

H. Mortimer is with the Science and Technology Facilities Council Rutherford Appleton Laboratory, Didcot OX11 0QX, UK (e-mail: hugh. mortimer@stfc.ac.uk).

R. Casa is with the Department of Agriculture, Forests, Nature and Energy (DAFNE), University of Tuscia, Viterbo 01100 , Italy (e-mail: rcasa@ unitus.it).

S. Pignatti and S. Pascucci are with the Institute of Methodologies for Environmental Analysis, National Research Council of Italy, Rome 00133, Italy. (e-mail: stefano.pignatti@cnr.it; simone.pascucci@cnr.it).

G. Laneve is with the Department of Astronautics, Electrics and Energetic, Sapienza University of Rome, Rome 00138, Italy (e-mail: giovanni.laneve@ uniroma1.it).

Color versions of one or more of the figures in this paper are available online at http://ieeexplore.ieee.org.

Digital Object Identifier 10.1109/JSTARS.2018.2813281 campaigns at Maccarese Farm (Central Rome, Italy), in which four crop types at four different growth stages were measured. We investigated the predictive power of nine VIs for crop LAI estimation, including NDVI, MSR, and $\mathrm{CI}_{\text {green }}$; the red-edge modified indices: $\mathrm{NDVI}_{\text {Red-edge }}, \mathrm{MSR}_{\text {Red-edge, }}$ and $\mathrm{CI}_{\text {Red-edge }}$ (generally represented by $\mathrm{VI}_{\text {Red-edge }}$ ); and the newly improved indices: $\mathrm{NDVI}_{\text {red\& } \mathrm{RE}}$, $M_{S R} R_{\text {red } \& E}$, and $C I_{\text {red\& } R E}$ (generally represented by $\left.V I_{\text {red\& } R E}\right)$. The results show that $V I_{\text {red\& } R E}$ improves the coefficient of determination $\left(R^{2}\right)$ for LAI estimation by $10 \%$ in comparison to $V I_{\text {Red-edge }}$ The newly improved indices prove to be the powerful alternatives for the LAI estimation of crops with wide chlorophyll range, and may provide valuable information for satellites equipped with red-edge channels (such as Sentinel-2) when applied to precision agriculture.

Index Terms-Precision agriculture, remote sensing, RapidEye, vegetation index (VI).

\section{INTRODUCTION}

$\mathbf{T}$ HE explicit quantification of vegetation biophysical variables on large spatial scales is an important aspect in agricultural management and monitoring [1]. For instance, knowledge of the spatial distribution of leaf area index (LAI) and chlorophyll content can be used to improve the use of resources, such as fertilizer and water [2], leading to better yields and reduced costs [3]-[6]. Remotely sensed data from satellites and airborne sensors has great potential to provide information on vegetation biophysical variables over large spatial and temporal scales. LAI, defined as one half the total leaf area per unit ground surface area [7], [8], is a biophysical key variable for estimating foliage cover and biomass production. The LAI can, therefore, be used to monitor and forecast crop growth and yield [1], [9], [10]. The LAI retrieval techniques from remote sensing data can be classified into three groups:

1) empirical retrieval methods, which typically relate the biophysical parameter of interest to spectral data [11], [12];

2) physical retrieval methods, which refers to inversion of radiative transfer models (RTM) from remote sensing observations [13];

3) hybrid methods, which aims to balance the strengths and weaknesses of empirical- and physical-based methods, e.g., through a machine learning approach [14].

Amongst the three groups, the empirical retrieval methods typically use vegetation indices (VIs) due to their simplicity, computational efficiency, and well-understood underlying mechanisms. The normalized difference vegetation index (NDVI) [15] is a widely used VI to estimate vegetation 


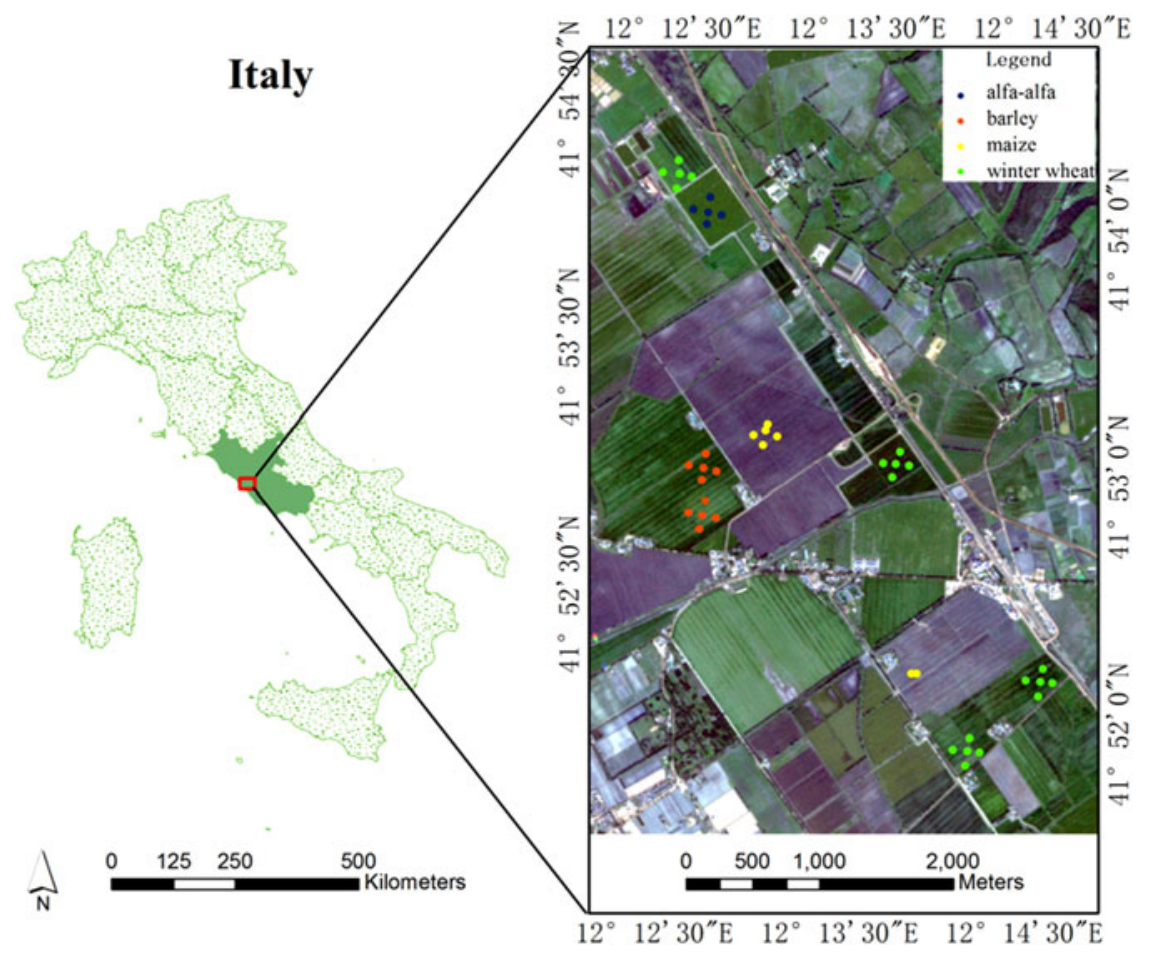

Fig. 1. Location of the field test sites at Maccarese Farm, Rome, Italy. The locations of the field plots where nondestructive LAI measurements took place are also shown. The highlighted image is a false color composite image from RapidEye collected on 18 March, 2015.

biophysical variables, relying on chlorophyll absorption in the red spectral region, creating low reflectance, and high reflectance in the near infrared (NIR) spectral region due to the scattering of light from the intercellular volume of leaf mesophyll. Nevertheless, one unavoidable limitation of NDVI is that the relationship between NDVI and LAI approaches saturation asymptotically under the condition of moderate-todense canopy (e.g., LAI $>3$ ) due to the inherent drawback of NDVI [16].

The red-edge region is defined as the spectral region between 680 and $750 \mathrm{~nm}$ where there is a sharp change in the vegetation reflectance [17]. This occurs due to the transition from chlorophyll absorption in the red region to cellular scattering in the NIR [18], [19]. The promise and potential of the red-edge spectral region for vegetation biophysical variable retrieval has motivated the design and also the launch of spaceborne imaging sensors involving red-edge bands, including hyperspectral satellites such as Hyperion, The Hyperspectral Imager for the Coastal Ocean, and The Compact High Resolution Imaging Spectrometer (CHRIS), and multispectral satellites such as MERIS, RapidEye, and recently, Sentinel-2 [19]. It has been demonstrated that in the red-edge spectral region the shape of the reflectance spectra is strongly influenced by LAI [20], [21]. The shift of red-edge position toward longer wavelengths is caused by an increase in leaf chlorophyll content [22]. Many studies have revealed that, within red and red-edge region, chlorophyll content and LAI contribute the most to PROSAIL simulated canopy reflectance [23], [24]. However, the effects of chlorophyll change on LAI retrieval are rarely discussed in studies using VIs based on red-edge reflectance for LAI estimation. To note that, in those studies, the red-edge modified indices improve the LAI estimation when the indices are applied to crops with consistent chlorophyll content, e.g., datasets consisting of one type of crop at one growth stage [19], [25]. Therefore, how chlorophyll content affects spectral reflectance and LAI when chlorophyll content and LAI vary simultaneously needs to be analyzed, e.g., datasets with multicrop species and across multigrowth stages. As such, the aims of this study are:

1) to analyze how variation in chlorophyll content and LAI contributes to red, red-edge, and NIR reflectance variability; and

2) to apply three improved spectral indices for LAI estimation, and evaluate their advantages over other existing VIs.

\section{EXPERIMENTAL AND VALIDATION DATA COLLECTION}

\section{A. Test Site Description and LAI Measurements}

Ground LAI measurements were carried out in situ at the Maccarese farm $\left(41^{\circ} 52^{\prime} \mathrm{N}, 12^{\circ} 13^{\prime} \mathrm{E}\right.$, alt. $8 \mathrm{~m}$ a.s.l.) near Rome, Central Italy (see Fig. 1) in 2015 growing season. The site is within a plain coastal agricultural area comprising four dominant crops: winter wheat (Triticum aestivum L.), barley (Hordeum vulgare $\mathrm{L}$.), alfalfa (Medicago sativa $\mathrm{L}$.), and maize (Zea mays L.) (see Table I). Winter wheat was measured on 3 March, 20 March, and 7 May, from its tillering stage to heading stage [26]; barley was measured on 3 March, 20 March, and 7 May, from its tillering stage to earning stage [27]; alfalfa was measured on 7 May, during its budding stage [28]; and maize was measured on 7 July, during its jointing stage [29]. The soil is Cutanic Luvisol, with a prevailing sandy clay loam texture, 
TABLE I

Field MeAsurements and CorResponding SATEllite Data ObTained

\begin{tabular}{lllll}
\hline \hline Data & & \multicolumn{3}{c}{ Time } \\
\hline $\begin{array}{l}\text { Field } \\
\text { measurements }\end{array}$ & $\begin{array}{l}\text { March 3 } \\
\text { (winter wheat, } \\
\text { barley) }\end{array}$ & $\begin{array}{l}\text { March 20 } \\
\text { (winter wheat, } \\
\text { barley) }\end{array}$ & $\begin{array}{l}\text { May 7 (winter } \\
\text { wheat, barley, } \\
\text { alfalfa) }\end{array}$ & $\begin{array}{l}\text { July 7 } \\
\text { (maize) }\end{array}$ \\
\hline $\begin{array}{l}\text { RapidEye } \\
\text { images }\end{array}$ & February 28 & March 18 & May 11 & July 5 \\
\hline \hline
\end{tabular}

becoming more clayey toward the north-east of the site. The climate is temperate Mediterranean with dry summers and wet autumns, with a yearly average temperature of $15.5^{\circ} \mathrm{C}$ and annual rainfall of $734 \mathrm{~mm}$. LAI Measurements were performed using an LAI-2200 Plant Canopy Analyzer (Li-Cor Biosciences Inc., Lincoln, NE, USA), at 66 points each covering $1 \mathrm{~m}^{2}$. To note that LAI measurements taken by LAI-2200 are "effective LAI' [30].

Due to the difficulties in collecting a large number of data in diffuse sunlight conditions, i.e., at sunset or dawn, which are considered optimal for LAI-2200 measurements, data were acquired during daytime in bright sunny days, within a maximum of four days since a satellite acquisition. A $45^{\circ}$ view cap was employed and the operator shaded the sensor from direct radiation. The sequence suggested by the manufacturer for direct radiation scattering correction was followed and a postprocessing correction was subsequently applied, using the FV2200 software (LI-COR Biosciences), as detailed in the equipment manual. Each LAI measurement was obtained, collecting ten readings from below the canopy, from an area of about $10 \mathrm{~m}^{2}$ of which the centre coordinates were recorded using a GPS with differential correction (accuracy in the order of 1-2 m).

\section{B. Satellite Data Acquisition and Processing}

Multispectral remote sensing images from the RapidEye sensor were obtained on 28 February, 18 March, 11 May, and 5 July 2015, corresponding to field measurements on 3 March, 20 March, 7 May, and 7 July (see Table I). This constellation of five identical EO satellites record radiance in five broad bands: blue $(440-510 \mathrm{~nm})$, green $(520-590 \mathrm{~nm})$, red $(630-685 \mathrm{~nm})$, red-edge $(690-730 \mathrm{~nm})$, and NIR $(760-850 \mathrm{~nm})$, at a spatial resolution of $5 \mathrm{~m}$.

The RapidEye images were delivered as level 3A Ortho Product, which offer the highest processing level with respect to radiometric, sensor, and geometric corrections. This means that the digital numbers of the image pixels represent calibrated radiance values. A subsequent atmospheric correction was performed on the RapidEye images by using the ENVI's Fast Line-of-Sight Atmospheric Analysis of Spectral Hypercubes (FLAASH) module, which is based on the RTM MODTRAN4 [31]. In this study, model parameters of a mid-latitude summer atmosphere and rural aerosols, as well as automatic aerosol retrieval, were used in FLAASH to correct the RapidEye images. The output of FLAASH assumed reflectance values rescaled to normal range of 0 to 1 .
TABLE II

PARAMETERS USED IN SIMUlating REFLECTANCE WITH PROSAIL MODEL

\begin{tabular}{lccc}
\hline \hline Parameter & Value & Units & Notes \\
\hline \multicolumn{4}{c}{ Leaf parameters } \\
\hline$N$ & 1.5 & - & Leaf thickness parameters \\
$C w$ & 0.01 & $\mathrm{~g} / \mathrm{cm}^{2}$ & Equivalent water thickness \\
$C m$ & 0.004 & $\mathrm{~g} / \mathrm{cm}^{2}$ & Dry matter content \\
$\mathrm{Cab}$ & $10 \sim 100$, step: 5 & $\mu \mathrm{g} / \mathrm{cm}^{2}$ & Cab \\
\hline \multicolumn{5}{c}{ Canopy parameters } & \\
\hline LAI & $1 \sim 9$, step: 0.5 & - & Leaf angle distribution \\
LAD & Spherical & - & Solar zenith angle \\
$\theta_{s}$ & 30 & degree & View zenith angle \\
$\theta_{v}$ & 0 & degree & View azimuth angle \\
$\phi$ & 0 & degree & View and \\
\hline \hline
\end{tabular}

\section{Reflectance Simulation With PROSPECT Model}

In order to analyze how variation in chlorophyll $\mathrm{a}+\mathrm{b}$ content $(\mathrm{Cab})$ and LAI contributes to canopy spectral reflectance, the combined leaf (PROSPECT) and canopy (SAIL) reflectance model PROSAIL was used for a sensitivity analysis of the spectral VIs. To investigate the effect of Cab and LAI on canopy spectral reflectance, chlorophyll content values were set to change from 10 to $100 \mu \mathrm{g} / \mathrm{cm}^{2}$ with a step of $5 \mu \mathrm{g} / \mathrm{cm}^{2}$, and LAI values were set to change from 1 to 9 with a step of 0.5 . The values of $\mathrm{Cab}$ and LAI cover their plausible range, respectively, based on our history field campaign data regarding the crop types investigated in this study. Equivalent water thickness $(C w)$ was fixed to a value of 0.01 , because the absorption of leaf water does not influence significantly the canopy reflectance within the spectral range used in this study $(<0.9 \mu \mathrm{m})$ [32]. Other input variables were assigned with fixed reasonable values based on field measurements and previous studies [33], [34] (see Table II).

\section{METHODS}

\section{A. Quantifying Sources of Variation in Simulated Reflectance Data}

A model sensitivity analysis was implemented to identify the significance of the LAI and chlorophyll content in explaining variance in the PROSAIL model output reflectance. The Extended Fourier Amplitude Sensitivity Test (EFAST) method was used [35], which is an extension of the classical Fourier Amplitude Sensitivity Test (FAST). The EFAST approach is a parametric transformation that enables reducing multidimensional integrals over the space of the input factors to one-dimensional quadratures, through a search curve that scans the whole input space. This approach allows the definition of a set of simulations in which all input parameters vary simultaneously. A Fourier decomposition is then conducted to obtain the fractional contribution of each input factor to the variance of the model output [36]. EFAST provides two sets of indices: first-order indices (FOI) and total-order indices (TOI). The FOI give the additive effect of each input factor; while the TOI are overall measures of importance, accounting for the effects of the interactions of each factor with others. 
TABLE III

DESCRIPTIONS AND FORMULAS OF VIS INVESTIGATED IN THIS STUdY

\begin{tabular}{|c|c|c|c|}
\hline Index & Description & Formula & Reference \\
\hline \multicolumn{4}{|c|}{ Existing indices } \\
\hline NDVI & NDVI & $\frac{\rho_{\mathrm{NIR}}-\rho_{\text {red }}}{\rho_{\mathrm{NIR}}+\rho_{\text {red }}}$ & {$[15]$} \\
\hline $\mathrm{NDVI}_{\text {Red-edge }}$ & Red-edge NDVI & $\frac{\rho_{\mathrm{NIR}}-\rho_{\mathrm{RE}}}{\rho_{\mathrm{NIR}}+\rho_{\mathrm{RE}}}$ & [41] \\
\hline MSR & MSR index & $\frac{\rho_{\text {NIR }} / \rho_{\text {red }}-1}{\sqrt{\rho_{\text {NIR }} / \rho_{\text {red }}+1}}$ & {$[38]$} \\
\hline $\mathrm{MSR}_{\text {Red-edge }}$ & Red-edge MSR index & $\frac{\rho_{\mathrm{NIR}} / \rho_{\mathrm{RE}}-1}{\sqrt{\rho_{\mathrm{NIR}} / \rho_{\mathrm{RE}}+1}}$ & {$[34]$} \\
\hline $\mathrm{CI}_{\text {green }}$ & Green CI & $\frac{\rho_{\mathrm{NIR}}}{\rho_{\text {green }}}-1$ & [42] \\
\hline $\mathrm{CI}_{\text {Red-edge }}$ & Red-edge CI & $\frac{\rho_{\mathrm{NIR}}}{\rho_{\mathrm{RE}}}-1$ & [43] \\
\hline \multicolumn{4}{|c|}{ Improved indices } \\
\hline $\mathrm{NDVI}_{\text {red\& RE }}$ & Red and red-edge NDVI & $\frac{\rho_{\mathrm{NIR}}-\left(a^{*} \rho_{\mathrm{red}}+(1-a)^{*} \rho_{\mathrm{RE}}\right)}{\rho_{\mathrm{NIR}}+\left(a^{*} \rho_{\mathrm{red}}+(1-a)^{*} \rho_{R E}\right)}$ & - \\
\hline $\mathrm{MSR}_{\mathrm{red} \& \mathrm{RE}}$ & Red and red-edge MSR index & $\frac{\rho_{\mathrm{NIR}} /\left(a^{*} \rho_{\mathrm{red}}+(1-a)^{*} \rho_{\mathrm{RE}}\right)-1}{\sqrt{\rho_{\mathrm{NIR}} /\left(a^{*} \rho_{\mathrm{red}}+(1-a)^{*} \rho_{\mathrm{R} \mathrm{E}}\right)+1}}$ & - \\
\hline$C \mathrm{I}_{\mathrm{red} \& \mathrm{RE}}$ & Red and red-edge modified CI & $\frac{\rho_{\mathrm{NIR}}}{a^{*} \rho_{\mathrm{red}}+(1-a)^{*} \rho_{\mathrm{R} \mathrm{E}}}-1$ & - \\
\hline
\end{tabular}

${ }^{*}$ NIR refers to near infrared; RE refers to red-edge; $a \in[0,1]$

Simulated spectral reflectance was analyzed to understand the effect of chlorophyll content on relationships between the LAI and the red, red-edge, and NIR reflectance. In order to quantify the effect of chlorophyll content on spectral indices, $\triangle \mathrm{RED}$, $\triangle \mathrm{RE}$, and $\triangle \mathrm{NIR}$ were formed as indicators to quantify the change of red, red-edge, and NIR bands against NIR spectral band under two different chlorophyll contents

$$
\begin{aligned}
\Delta \mathrm{RED} & =\left|\frac{\rho_{\mathrm{RED} 1}-\rho_{\mathrm{RED} 2}}{\rho_{\mathrm{NIR} 2}} \times 100 \%\right| \\
\Delta \mathrm{RE} & =\left|\frac{\rho_{\mathrm{RE} 1}-\rho_{\mathrm{RE} 2}}{\rho_{\mathrm{NIR} 2}} \times 100 \%\right| \\
\Delta \mathrm{NIR} & =\left|\frac{\rho_{\mathrm{NIR} 1}-\rho_{\mathrm{NIR} 2}}{\rho_{\mathrm{NIR} 2}} \times 100 \%\right|
\end{aligned}
$$

where $\rho_{\mathrm{RED} 1}, \rho_{\mathrm{RE} 1}$, and $\rho_{\mathrm{NIR} 1}$ are the spectral reflectance at red, red-edge, and NIR regions, respectively, under the one chlorophyll content, while $\rho_{\mathrm{RED} 2}, \rho_{\mathrm{RE} 2}$, and $\rho_{\mathrm{NIR} 2}$ are the spectral reflectance under the other chlorophyll content. To set up the EFAST sensitivity analysis and to compute $\triangle \mathrm{RED}, \triangle \mathrm{RE}$, and $\triangle \mathrm{NIR}$, the PROSAIL simulated spectral reflectance was spectrally resampled to the spectral response functions of RapidEye. (The spectral response functions of RapidEye were obtained from the RapidEye Science Archive website: https://resa.blackbridge.com/files/201406/Spectral_Response_Curves.pdf.)

\section{B. Existing and Improved VIs}

Canopy spectral reflectance data derived from RapidEye were used to calculate the VIs (see Table III) for subsequent LAI estimation. The existing tested VIs include three red/green reflectance based indices: NDVI, modified simple ratio index (MSR), and green chlorophyll index ( $\left.\mathrm{CI}_{\text {green }}\right)$. NDVI is widely accepted as a benchmark for comparing alternative inversion algorithms; it highlights the striking contrast between the NIR and red spectral reflectance [37]. MSR was proposed to suppress the saturation problem of NDVI [38]. $\mathrm{CI}_{\text {green }}$ shows a close relation to both chlorophyll content and LAI [39].

Additionally, three red-edge modified indices were tested, with red/green reflectance replaced with red-edge reflectance: $\mathrm{NDVI}_{\text {Red-edge }}$ (red-edge NDVI), MSR $\mathrm{Red-edge}_{\text {(red-edge MSR }}$ index), and $\mathrm{CI}_{\text {Red-edge }}$ (red-edge $\mathrm{CI}$ ). The red-edge modified indices $\left(\mathrm{NDVI}_{\text {Red-edge }}, \mathrm{MSR}_{\text {Red-edge }}\right.$, and $\left.\mathrm{CI}_{\text {Red-edge }}\right)$ have been shown to improve the LAI estimation compared to the red/green reflectance based indices, because the red-edge channel is sensitive to small changes in the canopy, gap fraction, and senescence [40].

In this study, we established three newly improved VIs combining red and red-edge spectral information: $\mathrm{NDVI}_{\mathrm{red} \& \mathrm{RE}}$ (red

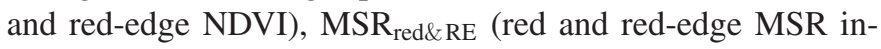
dex), and $\mathrm{CI}_{\text {red\&RE }}$ (red and red-edge $\mathrm{CI}$ ), in which a certain proportion of the red and the red-edge reflectance was used to replace the red/green reflectance in the formula of NDVI, MSR, and $\mathrm{CI}_{\text {green }}$. Following the principles of the original indices (NDVI, MSR, and $\mathrm{CI}_{\text {green }}$ ), the improved VIs (NDVI $\mathrm{I}_{\text {red\&RE }}$, $\mathrm{MSR}_{\mathrm{red} \& \mathrm{RE}}$, and $\mathrm{CI}_{\mathrm{red} \& \mathrm{RE}}$ ) still utilize the strong contrast between the red and NIR reflectance sensitive to LAI. Furthermore, combining red and red-edge spectral information is a compensation strategy that neither puts heavy emphasis on the red reflectance, which will help to avoid saturation, nor puts heavy emphasis on the red-edge reflectance, which will help to avoid interruption from the change of chlorophyll content [24]. The definitions and formulas of the improved indices as well as six existing indices tested in this study are shown in Table III.

\section{Noise Equivalent (NE) $\triangle L A I$}

The NE $\triangle$ LAI was used to test the sensitivity of the different spectral VIs against LAI changes. The NE $\Delta$ LAI has been proved to be advantageous over the direct comparison between 
TABLE IV

FIRST-ORDER AND TOTAL-ORDER SENSITIVITY INDICES FOR THE STUDY OF How VARIATION IN CAB AND LAICONTRIBUTES TO RED, RED-EDGE (RE), AND NIR REFLECTANCE VARIABILITY

\begin{tabular}{llccc}
\hline \hline & & Red & RE & NIR \\
\hline FOI (\%) & Cab & 65.60 & 93.31 & 0.41 \\
& LAI & 19.30 & 1.07 & 97.64 \\
TOI (\%) & Cab & 80.48 & 98.92 & 2.35 \\
& LAI & 33.69 & 6.59 & 99.66 \\
\hline \hline
\end{tabular}

different VIs, with different scales and dynamic ranges [44]. NE $\triangle \mathrm{LAI}$ is calculated as

$$
\mathrm{NE} \Delta \mathrm{LAI}=\frac{\mathrm{RMSE}\{\mathrm{VI} \text { versus LAI }\}}{d(\mathrm{VI}) / d(\mathrm{LAI})}
$$

where RMSE and $d(\mathrm{VI}) / d(\mathrm{LAI})$ are, respectively, the root mean square error and the first derivative of the best-fit function in the "VI versus LAI" relationship [2], [45]. The NE $\Delta$ LAI was calculated based on the "VI versus LAI" relationship function. The LAI was obtained from ground measurements as introduced in Section II-A, and the VI was calculated with the RapidEye data according to the formula in Table III.

\section{Validation Scheme}

Leave-one-out cross-validation procedure was used to evaluate the performance of the improved VIs to estimate LAI. This type of validation avoids the dependence on a single random partition into validation datasets. It also guarantees that all samples were used for both training and validation with each sample used for validation exactly once. The coefficient of determination $\left(R^{2}\right)$ and RMSE were selected as indicators of the accuracy of the statistical estimation models [46].

\section{RESUlTS AND DISCUSSION}

\section{A. Sensitivity of Canopy Reflectance Against LAI and Chlorophyll Content}

Table IV shows the FOI and TOI, calculated by the EFAST method introduced in Section III-A, for the study of how variation in Cab and LAI contributes to red, red-edge, and NIR reflectance variability. Table IV shows that, at the red spectral region, the sum of Cab and LAI EFAST FOI is about $85 \%$ (FOI of $\mathrm{Cab}=65.60 \%$, FOI of LAI $=19.30 \%$ ). This means that approximately $85 \%$ of the uncertainty in the PROSAIL model output red region reflectance is explained by the factors singularly, while the remaining $15 \%$ is explained by interactions between the two factors. Therefore, the EFAST TOI are provided (see Table IV) to account for the additive effects of each input factor and their interactions with the others.

The EFAST indices also show that the FOI and TOI of Cab at the red and red-edge region (FOI at the red/red-edge region: $65.60 \% / 93.31 \%$, TOI at the red/red-edge region: $80.48 \% /$ $98.92 \%$ ) are vastly larger than the corresponding indices of LAI at the red and red-edge region (FOI at the red/red-edge region: $19.30 \% / 1.07 \%$, TOI at the red/red-edge region: $33.69 \% / 6.59 \%$ ), suggesting that variation in the reflectance measured at the red and red-edge spectral region is mainly the result of variations in the chlorophyll content. Compared to the red spectral reflectance, the red-edge reflectance is more deeply controlled by the chlorophyll content, given that the FOI and TOI of $\mathrm{Cab}$ at the red-edge region (FOI: $93.31 \%$, TOI: $98.92 \%$ ) are larger than the indices at the red region (FOI: $65.60 \%$, TOI: $80.48 \%$ ). In contrast, variation in the NIR spectral reflectance is mainly the result of variations in LAI, because the EFAST indices of LAI at the NIR region (FOI: 97.64\%, TOI: 99.66\%) are vastly larger than the corresponding indices of Cab (FOI: $0.41 \%$, TOI: $2.35 \%$ ). The EFAST sensitivity analysis confirms that the rededge spectral reflectance is relatively easily affected by chlorophyll change than the red spectral reflectance, which means that the red-edge band will induce larger error for LAI retrieval when chlorophyll content varies simultaneously.

The PROSAIL simulated spectral reflectance was further analyzed to understand the relationships between the LAI and the red, red-edge, NIR reflectance (see Fig. 2). Fig. 2(a) shows that as LAI increases, the NIR reflectance increases, while the red reflectance decreases at early stage and then reached an asymptote when the LAI values exceeded three. Thus, both red reflectance and NDVI approach a saturation level asymptotically when LAI $>3$. The coefficient of determination $\left(R^{2}\right)$ of the relationship between NDVI and LAI in Fig. 2(a) is 0.81 for LAI $<3$, but drops to 0.04 for LAI $>3$. In addition, under visual comparison, the red-edge reflectance scatters most significantly due to chlorophyll content change, which is further supported by Fig. 2(b), where reflectance in red-edge appears as a sharp decrease when chlorophyll changes from 10 to $100 \mu \mathrm{g} / \mathrm{cm}^{2}$. In order to quantify the effect of chlorophyll content on spectral indices formed by the combination of red/NIR or red-edge/NIR spectral bands, $\triangle \mathrm{RED}, \triangle \mathrm{RE}$, and $\Delta$ NIR were defined as (1) through (3) in Section III-A, to quantify the relative change of each band. Fig. 2(c) demonstrates that when chlorophyll content varies from 10 to $100 \mu \mathrm{g} / \mathrm{cm}^{2}, \Delta \mathrm{RE}$ is much greater than $\triangle \mathrm{RED}$ and $\Delta \mathrm{NIR}$, which means that the relative change in red-edge spectral reflectance is larger than that in red and NIR. Therefore, VIs combining red-edge and NIR bands are more sensitive to chlorophyll change than the indices combining by red and NIR bands. For example, for simulated samples of LAI $=3$ in Fig. 2(a), the NDVI value is increased by $26.4 \%$ when Cab increases from $10 \mu \mathrm{g} / \mathrm{cm}^{2}(\mathrm{NDVI}=0.72)$ to $100 \mu \mathrm{g} / \mathrm{cm}^{2}(\mathrm{NDVI}=0.91)$; in contrast, the $\mathrm{NDVI}_{\text {red-edge }}$ value is increased by $159.3 \%$ when $\mathrm{Cab}$ increases from $10 \mu \mathrm{g} / \mathrm{cm}^{2}\left(\mathrm{NDVI}_{\text {red-edge }}=0.27\right)$ to $100 \mu \mathrm{g} / \mathrm{cm}^{2}\left(\mathrm{NDVI}_{\text {red-edge }}=0.70\right)$. The Cab variance would induce larger LAI retrieval error to $\mathrm{NDVI}_{\text {red-edge }}$ model than to NDVI model. Therefore, replacing the red/green reflectance with the red-edge reflectance in NDVI, MSR, and CI green $_{\text {[47], }}$ [48] does not necessarily improve the LAI estimation accuracy when applied to different crops at different growth stages in which the chlorophyll content and LAI vary together. Given that the red spectral reflectance saturates when LAI $>3$, while the red-edge region is easy to be affected by chlorophyll change, we recommend combining them into VIs rather than abandoning one of the two regions. 


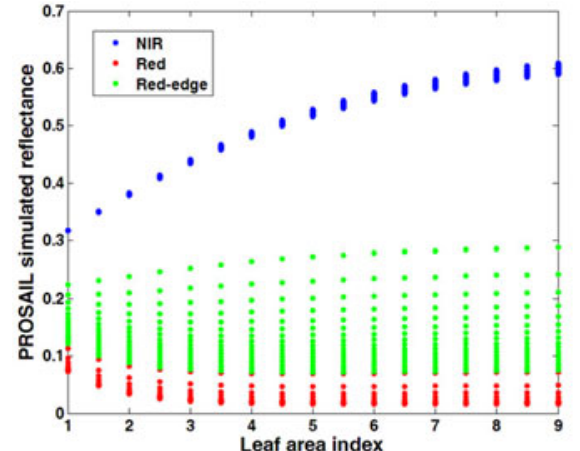

(a)

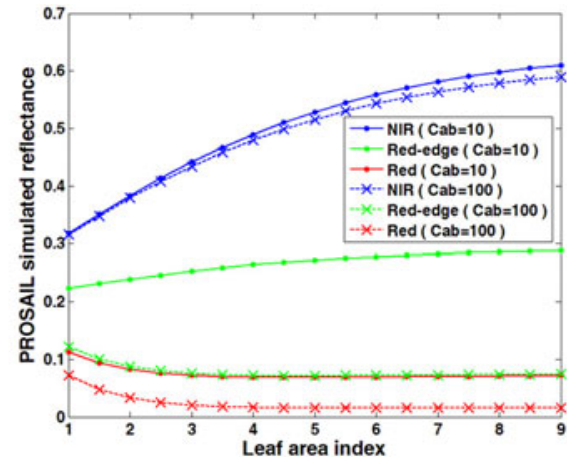

(b)

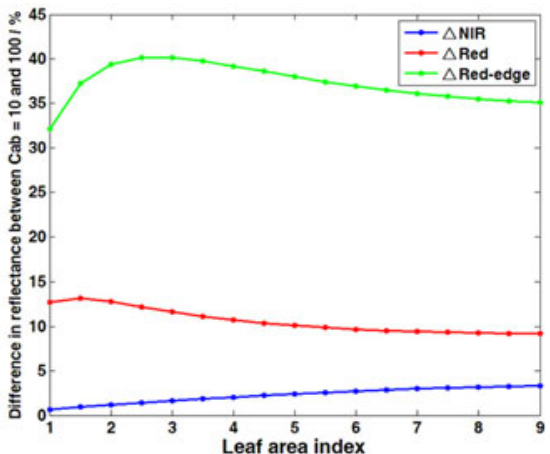

(c)

Fig. 2. Red, red-edge, and NIR reflectance response to LAI: (a) when chlorophyll content varies from 10 to $100 \mu \mathrm{g} / \mathrm{cm}^{2}$; (b) extracted from figure (a), when chlorophyll content is 10 and $100 \mu \mathrm{g} / \mathrm{cm}^{2}$; (c) the change of red, red-edge, and bands against NIR spectral band under two different chlorophyll contents [1)-(3)].

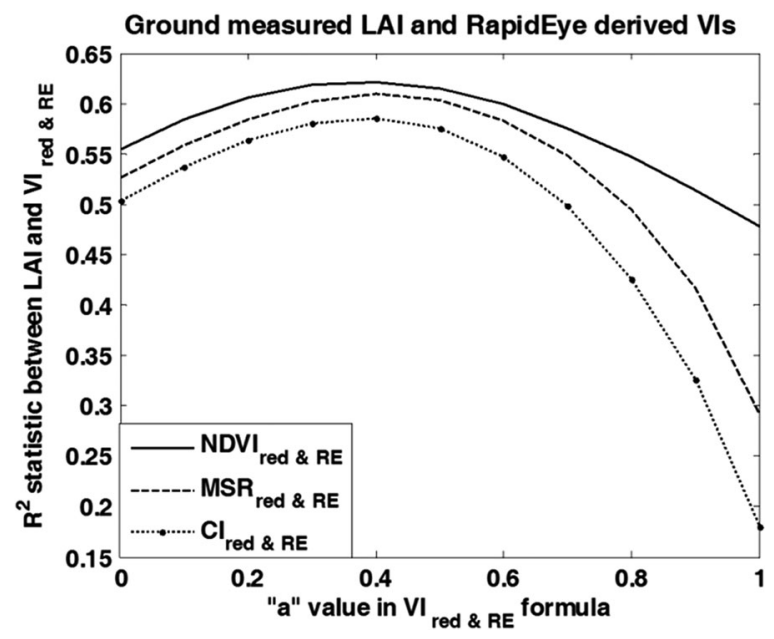

Fig. 3. Coefficient of determination of the calibration models for different values of the parameter $a$ (Table III), based on in-situ measured LAI and RapidEye derived reflectance. $\mathrm{VI}_{\mathrm{red} \& \mathrm{RE}}$ represents $\mathrm{NDVI}_{\mathrm{red} \& \mathrm{RE}}, \mathrm{MSR}_{\mathrm{red} \& \mathrm{RE}}, \mathrm{CI}$ red\&RE .

\section{B. Relationship Between VIs and LAI}

The analysis of the data in Table IV and Fig. 2 provides a justification to combine red and red-edge spectrum to formulate ratio VIs for LAI retrieval when chlorophyll content and LAI vary simultaneously. The improved indices in Table III were calculated using the RapidEye derived reflectance, with the parameter " $a$ " ranges from 0 to 1 , at a step of 0.1 . The value of parameter " $a$ " represents the proportion of red reflectance, and the value of $(1-a)$ represents the proportion of red-edge reflectance. The coefficient of determination $\left(R^{2}\right)$ of the calibration models based on improved indices $\left(\mathrm{NDVI}_{\mathrm{red} \& \mathrm{RE}}, \mathrm{MSR}_{\mathrm{red} \& \mathrm{RE}}, \mathrm{CI}_{\mathrm{red} \& \mathrm{RE}}\right)$ and in-situ measured LAI were calculated (see Fig. 3). The $R^{2}$ of each improved index peaked at $a=0.4\left(R^{2}\right.$ of $\mathrm{NDVI}_{\mathrm{red} \& \mathrm{RE}}=0.62, R^{2}$ of $\mathrm{MSR}_{\text {red } \& \mathrm{RE}}=0.61, R^{2}$ of $\left.\mathrm{CI}_{\text {red } \& \mathrm{RE}}=0.59\right)$, and the curve of each index followed the same trend: a small increase from $a=0\left(R^{2}\right.$ of $\mathrm{NDVI}_{\mathrm{red} \& \mathrm{RE}}=0.55, R^{2}$ of $\mathrm{MSR}_{\mathrm{red} \& \mathrm{RE}}=0.53$, $R^{2}$ of $\left.\mathrm{CI}_{\mathrm{red} \& \mathrm{RE}}=0.50\right)$ to $a=0.4$, then a reduction until $a$ $=1\left(R^{2}\right.$ of $\mathrm{NDVI}_{\mathrm{red} \& \mathrm{RE}}=0.48, R^{2}$ of $\mathrm{MSR}_{\mathrm{red} \& \mathrm{RE}}=0.29$, $R^{2}$ of $\left.\mathrm{CI}_{\text {red\& } \mathrm{RE}}=0.18\right)$. It is also noteworthy that each index achieved higher $R^{2}$ when $a=0$ compared to $a=1$, suggesting that replacing red/green reflectance with red-edge could enhance the relationship between LAI and VIs (see VIs formula of Table III), consistent with many research works [34], [41], [43], [47]. However, combining red and red-edge reflectance with selected proportion (in our case $a=0.4$, the percentage of red and red-edge reflectance were $40 \%$ and $60 \%$, respectively), further improves the correlation between LAI and VIs. To note that, the optimal proportion found between the red and red-edge reflectance in this study to maximize the LAI estimation may be varied for other types of agricultural systems, in which case we suggest to recompute the optimal proportion for other datasets.

The NDVI, NDVI $I_{\text {Red-edge, }}$ and NDVI $I_{\text {red } \& \text { RE }}$ exhibited logarithmic relationships with LAI, while MSR, MSR Red-edge, $_{\text {, }}$ $\mathrm{MSR}_{\text {red\&RE}}, \mathrm{CI}_{\text {green }}, \mathrm{CI}_{\text {Red-edge, }}$, and $\mathrm{CI}_{\text {red\&RE }}$ exhibited exponential relationships with LAI (see Fig. 4). The red/green reflectance based indices have weaker correlations with LAI, especially when LAI exceeded three. NDVI saturated as LAI value increased while MSR and $\mathrm{CI}_{\text {green }}$ showed considerable scatter against LAI. VI $\mathrm{I}_{\text {Red-edge }}$ (VI represents NDVI, MSR, and CI) with red/green reflectance replaced with red-edge has a stronger relationship with LAI than the red/green reflectance based indices; while $\mathrm{VI}_{\text {red\&RE }}$ combining red and red-edge reflectance had the strongest relationship with LAI, with $R^{2}$ values increased by at least $10 \%$ compared to $\mathrm{VI}_{\text {Red-edge }}$. Among the indices, $\mathrm{CI}_{\text {green }}$, which consists of NIR and green reflectance, had the lowest coefficient of determination $\left(R^{2}=0.063\right)$, suggesting that VIs including green reflectance are not optimal for LAI estimation under various chlorophyll content. Although green-based indices can be highly accurate when applied to single species plant communities [49].

For the same LAI, all the three red/green reflectance based indices (NDVI, MSR, and $\mathrm{CI}_{\text {green }}$ ) showed lower values for maize than other crops [see Fig. 4(a), (d), and (g)], all $\mathrm{VI}_{\text {Red-edge }}$

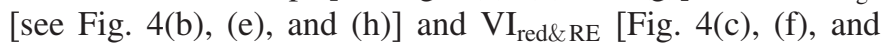
(i)] showed lower values for alfalfa than other crops. This is in agreement with the study of Delegido et al. [50], in which nine types of crops including, maize, alfalfa, and wheat were investigated based on field measurements in Spain, Germany, and France. This could be explained by the effect of chlorophyll 

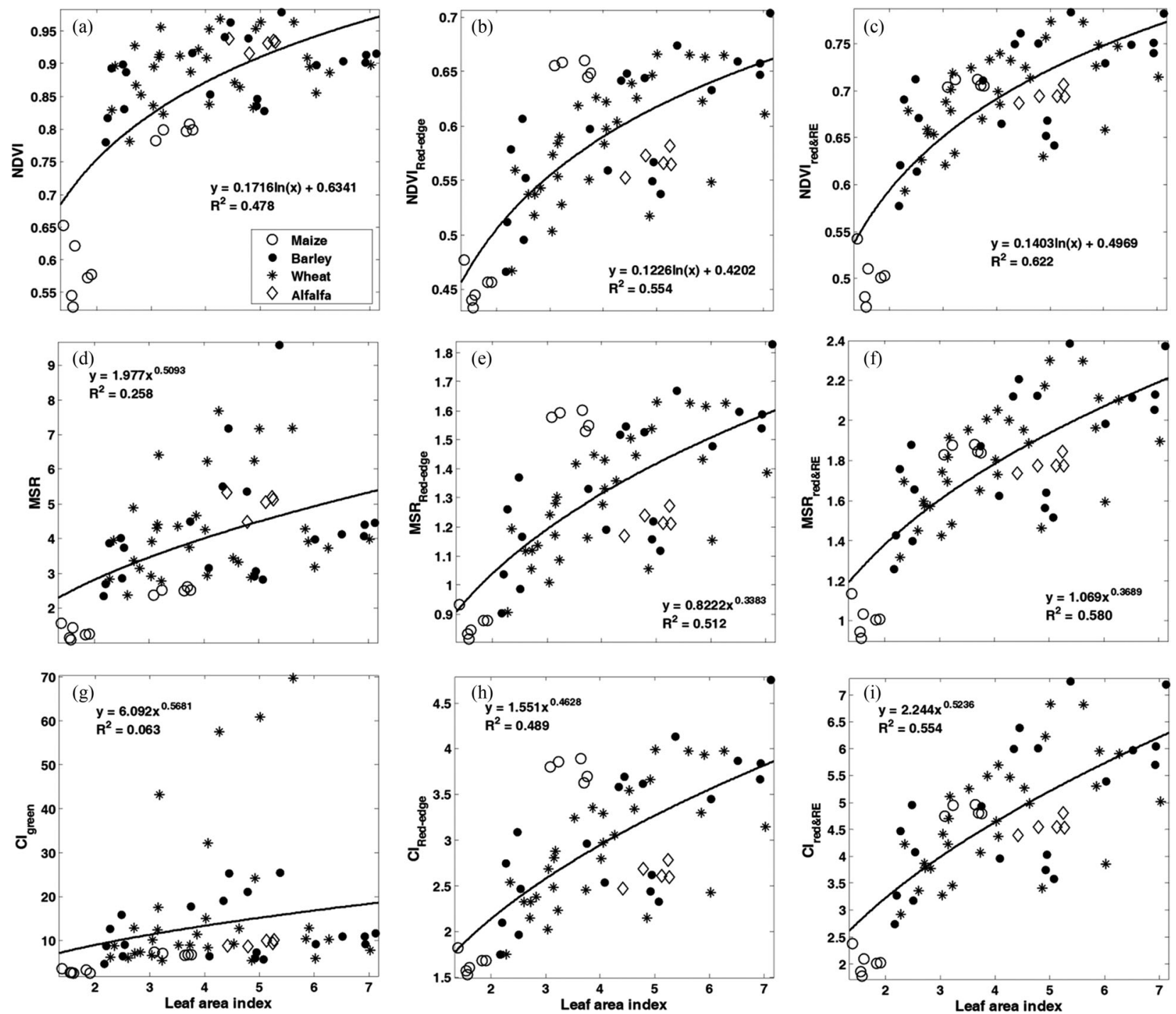

Fig. 4. Relationships between VIs [(a) NDVI, (b) NDVI ${ }_{\text {Red-edge }}$, (c) $\mathrm{NDVI}_{\text {red\& RE}}$, (d) MSR, (e) MSR Red-edge, (f) MSR $\mathrm{M}_{\text {red\& RE }}$, (g) CI $I_{\text {green }}$, (h) CI $I_{\text {Red-edge }}$, (i) $\left.\mathrm{CI}_{\text {red\& RE}}\right]$ and LAI, for maize, barley, wheat, and alfalfa during the growing seasons of 2015.

content. The in situ data we collected for this study does not include the chlorophyll content, therefore we have to refer the chlorophyll effects among these crops from other datasets and research works. According to other field measurements we have conducted and other research concerning these crops [50], [51], we can draw the conclusion that when at the same LAI value, usually the leaf chlorophyll content of maize is higher than that of wheat and barley, while the leaf chlorophyll content of alfalfa is lower than that of wheat and barley. As a result, the RapidEye reflectance in this study appears that the spectral reflectance of the red-edge is lower for maize than that in wheat and barley, while higher for alfalfa than that in wheat and barley, which is in accordance with the rule revealed by the simulated reflectance shown in Fig. 2; when the LAI value is fixed, the red-edge reflectance increases as the chlorophyll content decreases. In the red spectral region, the maize spectral reflectance is higher than that of other crops. Thus, the VI values for crops with equivalent LAI values (moderate-to-dense canopies) show that the maize canopy has lower VI (NDVI, MSR, $\mathrm{CI}_{\text {green }}$ ) values but higher $\mathrm{VI}_{\text {Red-edge }}\left(\mathrm{NDVI}_{\text {Red-edge }}, \mathrm{MSR}_{\text {Red-edge }}, \mathrm{CI}_{\text {Red-edge }}\right)$ than that of the other crops. In terms of alfalfa, the $\mathrm{VI}_{\text {Red-edge }}$ values are lower than other crops with the same LAI.

Crop canopy reflectance is a complex signal affected by many factors, besides the chlorophyll content, there might be other factors affecting LAI retrieval such as leaf structures and canopy architectures of these crops. For example, the canopies of maize and alfalfa exhibit a planophile leaf angle distribution [49], [52], while the canopies of barley and wheat exhibit a more erectophile leaf angle distribution [53]. But these factors have much less impact than LAI and chlorophyll content on canopy reflectance as proved by other researchers [24]. According to our other field measurements and other research works concerning these crops [50], [51], within the RapidEye bands we investigated [red (630-685 nm), red-edge $(690-730 \mathrm{~nm})$, NIR $(760-850 \mathrm{~nm})]$, the red and red-edge regions are dominated by $\mathrm{Cab}$ and LAI where other factors do not need to be accounted 


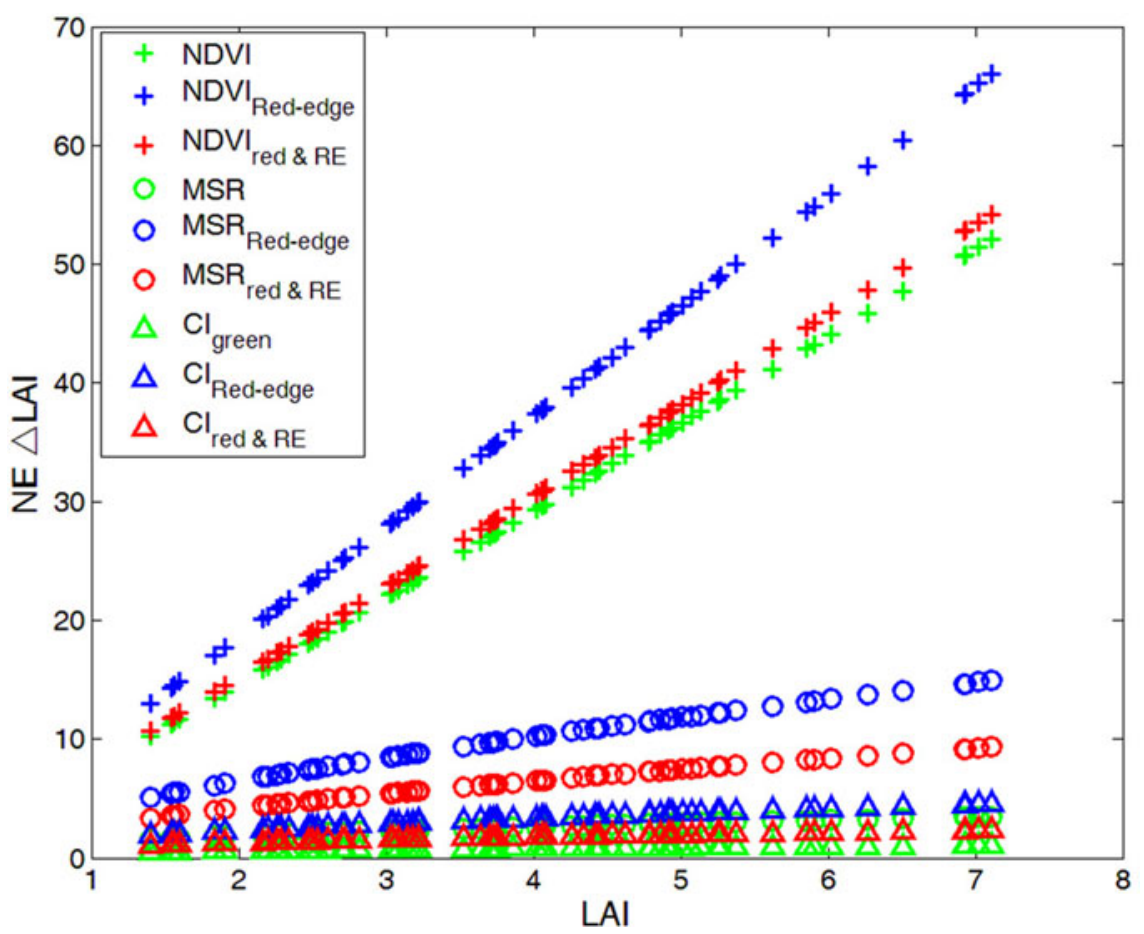

Fig. 5. Sensitivity of the different VIs tested to LAI using the NE $\Delta$ LAI (1).

for; the NIR region is impacted by multifactors, such as LAI, average leaf angle, and dry matter content, but these factors do not affect the improvement of the VIs proposed in our study. Because the NIR band remains unchanged during the improvement of VIs, in which the improvement relies on the combination of red and red-edge regions. In this study, the newly improved VIs are focused on reducing the impact of the chlorophyll content on LAI retrieval. Nevertheless, we suggest that the relationships between VIs and LAI will potentially be further improved if the impact from other factors could be reduced as well.

The sensitivity analysis of the different spectral VIs to LAI was performed by calculating the NE $\triangle \mathrm{LAI}$ of the calibration models between each VI and LAI, in order to compare the performance of the nine indices under the same criteria. This analysis (see Fig. 5) shows that among VIs of the same root (e.g., NDVI, NDVI Red-edge $_{\text {, and NDVI }}$ red\&RE), the NDVI exhibits the lowest NE $\Delta$ LAI values (thus the highest sensitivity to LAI).

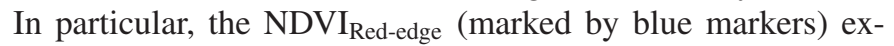
hibits the highest NE $\Delta$ LAI values (thus the lowest sensitivity to LAI), while the NDVI $\mathrm{I}_{\text {red } \& \text { RE }}$ shows moderate NE $\Delta$ LAI values (thus moderate sensitivity to LAI). MSR and $\mathrm{CI}_{\text {green }}$, as well as their corresponding improved indices, show the same rule as NDVI series indices: original VI (marked by green markers) was the most sensitive to LAI, second by the $\mathrm{VI}_{\text {red\&RE}}$, while the $\mathrm{VI}_{\text {Red-edge }}$ was the least sensitive to LAI. The spectral analysis confirms that $\mathrm{VI}_{\text {Red-edge }}$ is less sensitive to LAI than $\mathrm{VI}_{\mathrm{red} \& \mathrm{RE}}$. Therefore, the improved VIs $\mathrm{VI}_{\mathrm{red} \& \mathrm{RE}}(\mathrm{NDVI}$ red\&RE, $\mathrm{MSR}_{\text {red\&RE }}, \mathrm{CI}_{\text {red\&RE}}$ ) have greater potential in LAI retrieval than the corresponding $\mathrm{VI}_{\text {Red-edge }}\left(\mathrm{NDVI}_{\text {Red-edge }}, \mathrm{MSR}_{\text {Red-edge }}\right.$, $\left.\mathrm{CI}_{\text {Red-edge }}\right)$.

\section{LAI Estimation Model Validation}

Results of leave-one-out cross validation for LAI estimation are presented in Fig. 6, with coefficient of determination $\left(R^{2}\right)$ and RMSE computed and presented for each model. The estimated LAI values were compared with the ground measurements using least significant difference test performed using SPSS software [54]. Statistical analysis revealed that the estimates of $\mathrm{CI}_{\text {green }}$ model reached 0.05 level of significance, and estimates of other eight models reached 0.01 level of significance. Among the examined indices, the red/green reflectance based (VIs were the poorest at predicting LAI [see Fig. 6(a), (d), and (g)], the $\mathrm{VI}_{\text {Red-edge }}$ improved the LAI prediction [see Fig. 6(b), (e), and (h)] on the basis of VIs, by including rededge reflectance. This is agreed with other studies [19], [25] in which the red-edge modified indices improved the LAI estimation when the indices are applied to crops with consistent chlorophyll content, e.g., datasets consisting of one type of crop at one growth stage. However, the chlorophyll content varies across the crop growing season and varies among different crop types in our study, $\mathrm{VI}_{\text {red\&RE }}$ resulted in the best prediction with the lowest RMSE (less than 1.07) and the highest $R^{2}$ (above 0.500 ) [see Fig. 6(c), (f), and (I)], by combining the red spectral reflectance and the red-edge spectral reflectance into the VIs. In comparison with the $\mathrm{VI}_{\text {Red-edge }}$, the $\mathrm{VI}_{\text {red\& } \mathrm{RE}}$ improved the LAI estimation accuracy by at least $10 \%$ higher $R^{2}$ and $10 \%$ lower RMSE value. For instance, $\mathrm{NDVI}_{\text {red\&RE }}$ exhibited an $R^{2}$ of 0.500 and RMSE of 1.068; NDVI $\mathrm{I}_{\text {Red-edge }}$ exhibited an $R^{2}$ of 0.438 and RMSE of 1.138 , showing lower accuracy than NDVI $_{\text {red\& RE }}$; and NDVI exhibited an $R^{2}$ of 0.314 and RMSE of 1.255 , showing the lowest accuracy among NDVI, $\mathrm{NDVI}_{\text {Red-edge }}$, and NDVI $\mathrm{I}_{\mathrm{red} \& \mathrm{RE}}$. 

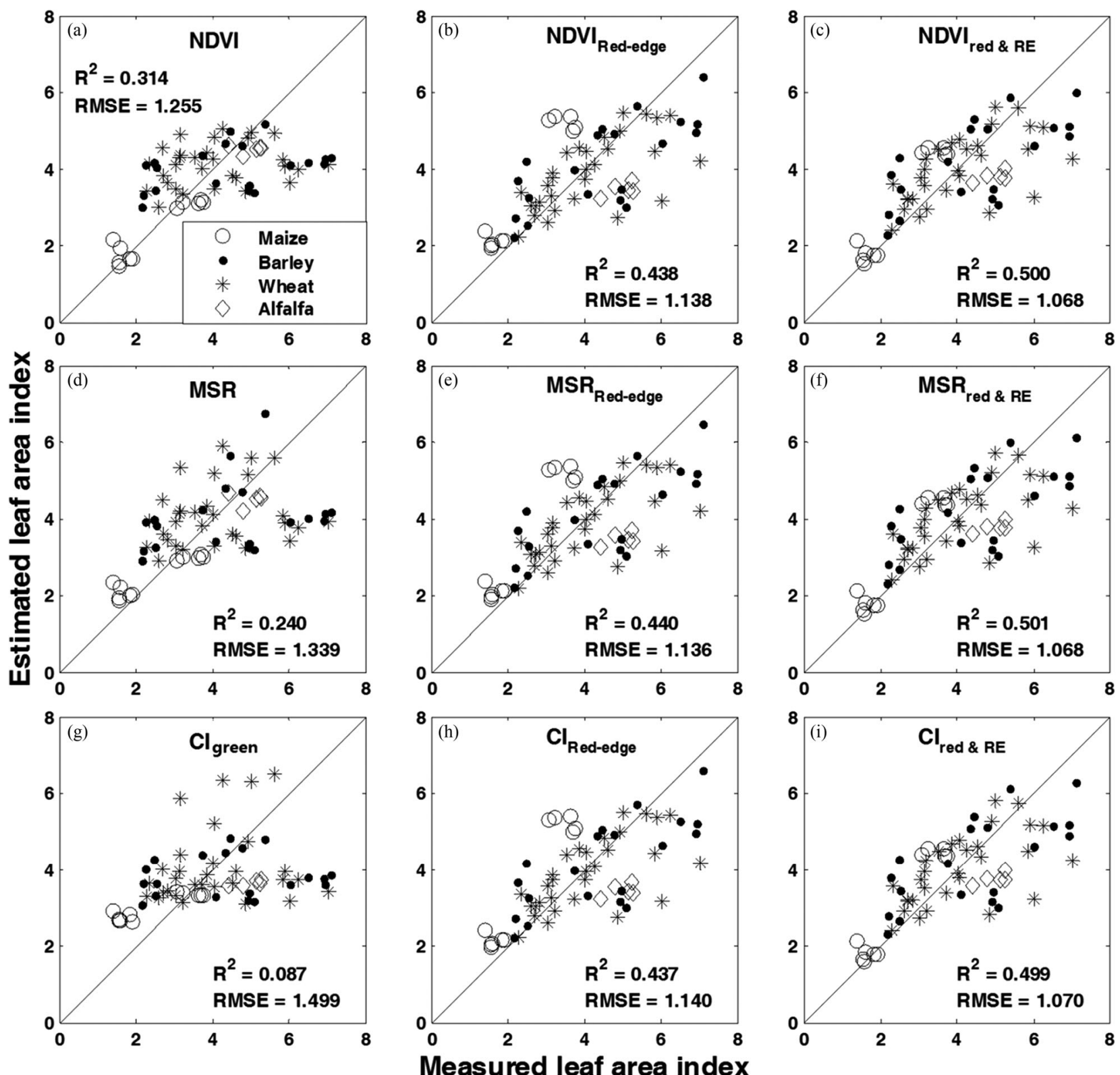

Fig. 6. Measured LAI versus estimated LAI derived from RapidEye spectra. (a) NDVI, (b) NDVI Red-edge, (c) NDVI ${ }_{\text {red\&RE}}$, (d) MSR, (e) MSR Red-edge, (f) $\mathrm{MSR}_{\text {red } \& \mathrm{RE}},(\mathrm{g}) \mathrm{CI}_{\text {green }}$, (h) $\mathrm{CI}_{\text {Red-edge }}$, and (i) $\mathrm{CI}_{\text {red } \& \mathrm{RE}}$.

The red/green reflectance based indices (VIs) exhibited respective drawbacks; for instance, the NDVI saturated when LAI exceeds three, MSR scattered when LAI exceeds three, and the $\mathrm{CI}_{\text {green }}$ overestimated LAI at low-to-moderate $(\mathrm{LAI}<3)$ canopy cover whilst significantly underestimated LAI when LAI $>3$. The saturation of NDVI at LAI values higher than three was expected and is in agreement with the literature [16]. The red-edge-based indices $\mathrm{VI}_{\text {Red-edge }}$ improved the estimation by alleviating the underestimation of moderate-to-dense canopy, but did not improved much overestimation for low-to-moderate canopy, agreeing with the results in other research works using the red-edge-based indices [48], [50]. By accounting for the chlorophyll content effect, the improved VIs we formed in this paper best yielded LAI with highest accuracy and robustness when applied to a wide range of crops across multigrowth stages.

In addition, the effects of chlorophyll content difference among the four crop species on canopy spectra and VIs, discussed in Section IV-B, result in the different behaviour in LAI estimation. The maize and alfalfa LAI are better estimated by $\mathrm{VI}_{\text {Red-edge }}$ [see Fig. 6(b), (e), and (h)] than by the VI [Fig. 6(b), (e), and (h)], because the red-edge reflectance is significantly affected by the chlorophyll content: the red-edge reflectance of maize is lower than that of wheat and barley, while the red-edge reflectance of alfalfa is higher than that of wheat and barley. Hence replacing the red band with red-edge in VIs loose the robustness of VIs against chlorophyll change. Fig. 6(c), (f), and (i) demonstrates that $V I_{r e d \& R E}$ better retrieved maize and alfalfa 
LAI than $\mathrm{VI}_{\text {Red-edge }}$, and $\mathrm{VI}_{\text {red\&RE }}$ improved the underestimation and overestimation problems of VIs, confirming that combining red and red-edge reflectance in $\mathrm{VI}_{\mathrm{red} \& \mathrm{RE}}$ could improve the underestimation and overestimation problems, whilst remain a certain capability of robustness against chlorophyll change. Our results agreed with many researchers who revealed that some indices using red-edge bands in their formulation, however, proved to be less sensitive to differences among species [43], [49]. As the performance of empirical methods are case dependent, we suggest using our improved indices $\left(\mathrm{VI}_{\mathrm{red} \& \mathrm{RE}}\right)$ for the case of various chlorophyll content, e.g., various crop species and various growth stages. For complicated cases, a threshold method to choose among our improved indices, rededge indices ( $\mathrm{VI}_{\text {Red-edge }}$ ) and original indices (VI) may yield higher LAI estimation accuracy. For example, on the choice between NDVI and red-edge NDVI, Nguy-Robertson et al. selected NDVI $=0.7$ as a threshold for their case of maize and soybean LAI estimation (NDVI saturates at 0.7) [55].

\section{CONCLUSION}

In this paper, we have proposed three improved VIs (NDVI $I_{\text {red\&RE }}, \mathrm{MSR}_{\text {red\&RE }}$, and $\mathrm{CI}_{\text {red\&RE}}$ ) combining the red and red-edge spectral region and validated them with the RapidEye satellite data and in-situ data over four crops at four growth stages. The predictive power of the three improved VIs and other six existing indices have been analyzed, including three $\mathrm{red} /$ green reflectance based indices (NDVI, MSR, and $\mathrm{CI}_{\text {green }}$ ), three red-edge modified indices $\left(\mathrm{NDVI}_{\text {Red-edge }}, \mathrm{MSR}_{\text {Red-edge }}\right.$, and $\left.\mathrm{CI}_{\text {Red-edge }}\right)$, and three improved indices combining red and rededge regions $\left(\mathrm{NDVI}_{\mathrm{red} \& \mathrm{RE}}, \mathrm{MSR}_{\mathrm{red} \& \mathrm{RE}}\right.$, and $\left.\mathrm{CI}_{\mathrm{red} \& \mathrm{RE}}\right)$. The proportion between the red and red-edge reflectance that led to the best correlation between $\mathrm{VI}_{\text {red\&RE }}\left(\mathrm{NDVI}_{\text {Red-edge }}, \mathrm{MSR}_{\text {Red-edge }}\right.$, and $\mathrm{CI}_{\text {Red-edge }}$ ) and LAI was encountered at 0.4 , which means using $0.4^{*} \rho_{\text {red }}+0.6^{*} \rho_{\mathrm{RE}}$ to replace $\rho_{\text {red }}$ in the formula of $\mathrm{red} /$ green reflectance based indices (NDVI, MSR, and $\mathrm{CI}_{\text {green }}$ ). Under the comparison amongst the red/green reflectance based indices, the $\mathrm{VI}_{\text {Red-edge }}$ and the $\mathrm{VI}_{\text {red\&RE }}$, the $\mathrm{VI}_{\text {red\&RE }}$ achieved the most accurate LAI estimation, improving at least $10 \%$ the coefficient of determination achieved by $\mathrm{VI}_{\text {Red-edge }}$. The improved indices $\mathrm{VI}_{\mathrm{red} \& \mathrm{RE}}$, combining the red and red-edge reflectance, both of the spectral regions are strongly related to the physiological status of the plant, proved to be the most robust and stable for crop LAI estimation over a wide range of crop species and growth stages.

Such indices are of great potential for agricultural monitoring using sensors providing red-edge bands and high spatial resolution, such as RapidEye and the newly launched Sentinel-2. In view of delivering improved LAI products for environmental and agricultural applications, further research is planned in the directions of:

1) validation of the proposed VIs over a broader range of crops with field collected both LAI and chlorophyll content;

2) application and evaluation of more advanced plant parameter retrieval models.

\section{ACKNOWLEDGMENT}

The authors would like to thank Dr. G. Cooper, the University of Southampton, for his dedication in the English language modification for this paper. Thanks must also be extended to the editors and reviewers who handled our paper.

\section{REFERENCES}

[1] W. Dorigo, R. Zurita-Milla, A. J. de Wit, J. Brazile, R. Singh, and M. E. Schaepman, "A review on reflective remote sensing and data assimilation techniques for enhanced agroecosystem modeling," Int. J. Appl. Earth Observ. Geoinf., vol. 9, no. 2, pp. 165-193, 2007.

[2] Q. Xie et al., "Evaluating the potential of vegetation indices for winter wheat LAI estimation under different fertilization and water conditions," Adv. Space Res., vol. 56, no. 11, pp. 2365-2373, 2015.

[3] H. Bu, L. Sharma, A. Denton, and D. Franzen, "Comparison of Satellite imagery and ground-based active optical sensors as yield predictors in sugar beet, spring wheat, corn, and sunflower," Agronomy J., vol. 109, no. 1, pp. 299-308, 2017.

[4] L. K. Sharma, H. Bu, D. W. Franzen, and A. Denton, "Use of corn height measured with an acoustic sensor improves yield estimation with ground based active optical sensors," Comput. Electron. Agriculture, vol. 124, pp. $254-262,2016$.

[5] L. Sharma and D. Franzen, "Use of corn height to improve the relationship between active optical sensor readings and yield estimates," Precision Agriculture, vol. 15, no. 3, pp. 331-345, 2014.

[6] D. W. Franzen, L. K. Sharma, and H. Bu, Active optical sensor algorithms for corn yield prediction and a corn side-dress nitrogen rate aid," North Dakota State Univ., Fargo, ND, USA, NDSU Extension Service, 2014.

[7] J. Chen and T. Black, "Measuring leaf area index of plant canopies with branch architecture," Agricultural Forest Meteorol., vol. 57, nos. 1-3, pp. 1-12, 1991.

[8] J. M. Chen and T. Black, "Defining leaf area index for non-flat leaves," Plant, Cell Environ., vol. 15, no. 4, pp. 421-429, 1992.

[9] R. Casa, H. Varella, S. Buis, M. Guérif, B. De Solan, and F. Baret, "Forcing a wheat crop model with LAI data to access agronomic variables: Evaluation of the impact of model and LAI uncertainties and comparison with an empirical approach," Eur. J. Agronomy, vol. 37, no. 1, pp. 1-10, 2012.

[10] L. K. Sharma, S. K. Bali, J. D. Dwyer, A. B. Plant, and A. Bhowmik, "A case study of improving yield prediction and sulfur deficiency detection using optical sensors and relationship of historical potato yield with weather data in maine," Sensors, vol. 17, no. 5, 2017, Art. no. 1095.

[11] R. Pu and J. Cheng, "Mapping forest leaf area index using reflectance and textural information derived from WorldView-2 imagery in a mixed natural forest area in Florida, US," Int. J. Appl. Earth Observ. Geoinf., vol. 42, pp. 11-23, 2015.

[12] J. Liu, E. Pattey, and J. Guillaume, "Assessment of vegetation indices for regional crop green LAI estimation from Landsat images over multiple growing seasons," Remote Sens. Environ., vol. 123, pp. 347-358, 2012.

[13] J. Verrelst, J. P. Rivera, G. Leonenko, L. Alonso, and J. Moreno, "Optimizing LUT-based RTM inversion for semiautomatic mapping of crop biophysical parameters from Sentinel 2 and 3 data role of cost functions," vol. 52, no. 1, pp. 257-267, 2014.

[14] J. Verrelst et al., "Machine learning regression algorithms for biophysical parameter retrieval: Opportunities for Sentinel-2 and -3," Remote Sens. Environ., vol. 118, pp. 127-139, 2012.

[15] J. Rouse, Jr., R. Haas, J. Schell, and D. Deering, "Monitoring vegetation systems in the great plains with ERTS," NASA, Washington, DC, USA, vol. 351, pp. 309-317, 1974.

[16] D. Haboudane, J. R. Miller, E. Pattey, P. J. Zarco-Tejada, and I. B. Strachan, "Hyperspectral vegetation indices and novel algorithms for predicting green LAI of crop canopies: Modeling and validation in the context of precision agriculture," Remote Sens. Environ., vol. 90, no. 3, pp. 337-352, 2004.

[17] D. Horler, M. Dockray, and J. Barber, "The red edge of plant leaf reflectance," Int. J. Remote Sens., vol. 4, no. 2, pp. 273-288, 1983.

[18] J. Clevers et al., "Derivation of the red edge index using the MERIS standard band setting," Int. J. Remote Sens., vol. 23, no. 16, pp. 3169$3184,2002$.

[19] J. Delegido, J. Verrelst, C. Meza, J. Rivera, L. Alonso, and J. Moreno, “A red-edge spectral index for remote sensing estimation of green LAI over agroecosystems," Eur. J. Agronomy, vol. 46, pp. 42-52, 2013. 
[20] K.-S. Lee, W. B. Cohen, R. E. Kennedy, T. K. Maiersperger, and S. T. Gower, "Hyperspectral versus multispectral data for estimating leaf area index in four different biomes," Remote Sens. Environ., vol. 91, no. 3, pp. 508-520, 2004.

[21] L. K. Sharma, "Evaluation of active optical ground-based sensors to detect early nitrogen deficiencies in corn," Ph.D. dissertation, North Dakota State Univ., Fargo, ND, USA, 2014.

[22] J. Dash and P. J. Curran, "The MERIS terrestrial chlorophyll index," Int. J. Remote Sens., vol. 25, no. 23, pp. 5403-5413, 2004.

[23] X. Yanfang, Z. Demin, G. Huili, and Z. Wenji, "Sensitivity of canopy reflectance to biochemical and biophysical variables," J. Remote Sens., vol. 19, no. 3, pp. 368-374, 2015.

[24] Y. Fei et al., "Comparison of different methods for corn LAI estimation over northeastern China," Int. J. Appl. Earth Observ. Geoinf., vol. 18, pp. 462-471, 2012.

[25] L. K. Sharma, H. Bu, A. Denton, and D. W. Franzen, "Active-optical sensors using red NDVI compared to red edge NDVI for prediction of corn grain yield in North Dakota, USA," Sensors, vol. 15, no. 11, pp. 27832 $27853,2015$.

[26] E. Kanemasu, C. Niblett, H. Manges, D. Lenhert, and M. Newman, "Wheat: Its growth and disease severity as deduced from ERTS-1," Remote Sens. Environ., vol. 3, no. 4, pp. 255-260, 1974.

[27] A. Vassilev, T. Tsonev, and I. Yordanov, "Physiological response of barley plants (Hordeum vulgare) to cadmium contamination in soil during ontogenesis," Environ. Pollution, vol. 103, no. 2, pp. 287-293, 1998.

[28] B. Niwinska, J. Strzetelski, J. Kowalczyk, F. Borowiec, and P. Domanski, "The effect of phenological stage and season on nutritive value, chemical composition and nutrient digestibility of lucerne (Medicago sativa L.) green forage in the alimentary tract of cattle," Czech J. Animal Sci., vol. 50, no. 11, pp. 511-518, 2005

[29] L. Yi, Y. Shenjiao, L. Shiqing, C. Xinping, and C. Fang, "Growth and development of maize (Zea mays L.) in response to different field water management practices: Resource capture and use efficiency," Agricultural Forest Meteorol., vol. 150, no. 4, pp. 606-613, 2010.

[30] J. D. White, S. W. Running, R. Nemani, R. E. Keane, and K. C. Ryan, "Measurement and remote sensing of LAI in rocky mountain montane ecosystems," Can. J. Forest Res., vol. 27, no. 11, pp. 1714-1727, 1997.

[31] M. W. Matthew et al., "Atmospheric correction of spectral imagery: Evaluation of the FLAASH algorithm with AVIRIS data," in Proc. Appl. Imagery Pattern Recognit. Workshop, 2002, pp. 157-163.

[32] C. Atzberger and K. Richter, "Spatially constrained inversion of radiative transfer models for improved LAI mapping from future Sentinel-2 imagery," Remote Sens. Environ., vol. 120, pp. 208-218, 2012.

[33] X. Zhou, W. Huang, W. Kong, H. Ye, Y. Dong, and R. Casa, "Assessment of leaf carotenoids content with a new carotenoid index: Development and validation on experimental and model data," Int. J. Appl. Earth Observ. Geoinf., vol. 57, pp. 24-35, 2017.

[34] C. Wu, Z. Niu, Q. Tang, and W. Huang, "Estimating chlorophyll content from hyperspectral vegetation indices: Modeling and validation," Agricultural Forest Meteorol., vol. 148, no. 8-9, pp. 1230-1241, 2008.

[35] A. Saltelli, "Sensitivity analysis: Could better methods be used?," J. Geophys. Res., Atmos., vol. 104, no. D3, pp. 3789-3793, 1999.

[36] P. Bowyer and F. Danson, "Sensitivity of spectral reflectance to variation in live fuel moisture content at leaf and canopy level," Remote Sens. Environ., vol. 92, no. 3, pp. 297-308, 2004.

[37] Q. Xie et al. "Leaf area index estimation using vegetation indices derived from airborne hyperspectral images in winter wheat," IEEE J. Sel. Topics Appl. Earth Observ. Remote Sens., vol. 7, no. 8, pp. 3586-3594, Aug. 2014.

[38] J. M. Chen, "Evaluation of vegetation indices and a modified simple ratio for boreal applications," Can. J. Remote Sens., vol. 22, no. 3, pp. 229-242, 1996.

[39] A. L. Nguy-Robertson et al., "Estimating green LAI in four crops: Potential of determining optimal spectral bands for a universal algorithm," Agricultural Forest Meteorol., vol. 192, pp. 140-148, 2014.

[40] C. Potter, S. Li, S. Huang, and R. L. Crabtree, "Analysis of sapling density regeneration in Yellowstone National Park with hyperspectral remote sensing data," Remote Sens. Environ., vol. 121, pp. 61-68, 2012.

[41] A. Gitelson and M. N. Merzlyak, "Spectral reflectance changes associated with autumn senescence of Aesculus hippocastanum L. and Acer platanoides L. leaves. Spectral features and relation to chlorophyll estimation," J. Plant Physiol., vol. 143, no. 3, pp. 286-292, 1994.

[42] A. A. Gitelson, Y. Gritz, and M. N. Merzlyak, "Relationships between leaf chlorophyll content and spectral reflectance and algorithms for nondestructive chlorophyll assessment in higher plant leaves," J. Plant Physiol., vol. 160, no. 3, pp. 271-282, 2003.
[43] A. A. Gitelson, A. Vina, V. Ciganda, D. C. Rundquist, and T. J. Arkebauer "Remote estimation of canopy chlorophyll content in crops," Geophys. Res. Lett., vol. 32, no. 8, 2005, Art. no. L08403.

[44] A. Viña and A. A. Gitelson, "New developments in the remote estimation of the fraction of absorbed photosynthetically active radiation in crops," Geophys. Res. Lett., vol. 32, no. 17, 2005, Art. no. L17403.

[45] Y. M. Govaerts, M. M. Verstraete, B. Pinty, and N. Gobron, "Designing optimal spectral indices: A feasibility and proof of concept study," Int. J. Remote Sens., vol. 20, no. 9, pp. 1853-1873, 1999.

[46] Q. Xie et al., "Estimating winter wheat leaf area index from ground and hyperspectral observations using vegetation indices," IEEE J. Sel. Topics Appl. Earth Observ. Remote Sens., vol. 9, no. 2, pp. 771-780, Feb. 2016.

[47] A. Tillack, A. Clasen, B. Kleinschmit, and M. Förster, "Estimation of the seasonal leaf area index in an alluvial forest using high-resolution satellitebased vegetation indices," Remote Sens. Environ., vol. 141, pp. 52-63, 2014.

[48] J. Delegido, J. Verrelst, C. M. Meza, J. P. Rivera, L. Alonso, and J. Moreno, "A red-edge spectral index for remote sensing estimation of green LAI over agroecosystems," Eur. J. Agronomy, vol. 46, pp. 42-52, 2013.

[49] A. Viña, A. A. Gitelson, A. L. Nguy-Robertson, and Y. Peng, "Comparison of different vegetation indices for the remote assessment of green leaf area index of crops," Remote Sens. Environ., vol. 115, no. 12, pp. 3468-3478, 2011.

[50] J. Delegido, J. Verrelst, L. Alonso, and J. Moreno, "Evaluation of Sentinel2 red-edge bands for empirical estimation of green LAI and chlorophyll content," Sensors (Basel), vol. 11, no. 7, pp. 7063-7081, 2011.

[51] M. González-Sanpedro, T. Le Toan, J. Moreno, L. Kergoat, and E. Rubio, "Seasonal variations of leaf area index of agricultural fields retrieved from Landsat data," Remote Sens. Environ., vol. 112, no. 3, pp. 810-824, 2008

[52] J. Kirchner, D. Kimes, and J. McMurtrey, "Variation of directional reflectance factors with structural changes of a developing alfalfa canopy," Appl. Opt., vol. 21, no. 20, pp. 3766-3774, 1982.

[53] R. Houborg and E. Boegh, "Mapping leaf chlorophyll and leaf area index using inverse and forward canopy reflectance modeling and SPOT reflectance data," Remote Sens. Environ., vol. 112, no. 1, pp. 186-202, 2008.

[54] B. C. Cronk, How to Use SPSS: A Step-By-Step Guide to Analysis and Interpretation. Evanston, IL, USA: Routledge, 2017.

[55] A. Nguy-Robertson, A. Gitelson, Y. Peng, A. Viña, T. Arkebauer, and D. Rundquist, "Green leaf area index estimation in maize and soybean: Combining vegetation indices to achieve maximal sensitivity," Agronomy J., vol. 104, no. 5, pp. 1336-1347, 2012.

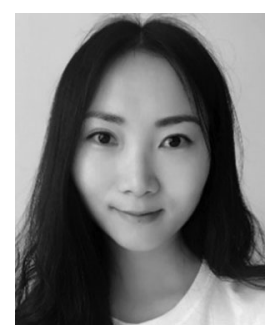

Qiaoyun Xie received the Ph.D. degree in cartography and GIS from the Institute of Remote Sensing and Digital Earth, Chinese Academy of Sciences, Beijing, China, in 2017. Her Ph.D. degree was joint trained by the Department of Geography and Environment, University of Southampton, Southampton, U.K.

She is currently a Research Associate with the Climate Change Cluster (C3), Faculty of Science, University of Technology Sydney, Sydney, N.S.W., Australia. Her main research interests include using remote sensing for vegetation monitoring, including vegetation parameter retrieval, vegetation dynamics, landscape phenology processes, and their shifting seasonalities with climate variability.

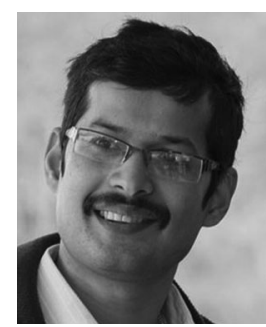

Jadu Dash received the Ph.D. degree from the University of Southampton, Southampton, U.K., in 2005.

$\mathrm{He}$ is currently a Professor in remote sensing with the Department of Geography and Environment, University of Southampton. He has been a staff member with the Department Geography and Environment, since 2006. He has a strong research background in pure and applied remote sensing, particularly in algorithm development and validation of biophysical products from EO data, spatio-temporal analysis of EO data to understand the state of the world's ecosystems and to study the impact of climate change on the ecosystem. 


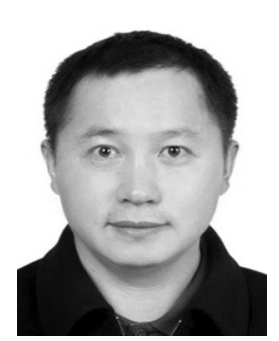

Wenjiang Huang received the Ph.D. degree in cartography and GIS from Beijing Normal University, Beijing, China, in 2005.

He is currently a Professor with the Key Laboratory of Digital Earth Science, Institute of Remote Sensing and Digital Earth, Chinese Academy of Sciences, Beijing. His research interests include quantitative remote sensing research and application in vegetation.

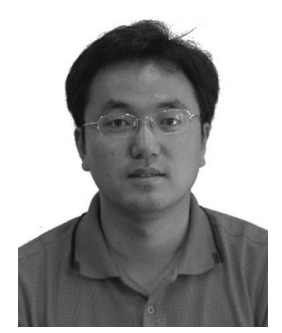

Dailiang Peng received the B.S. degree in agricultural resources and environment from Anhui Science and Technology University, Bengbu, China, in 2009 and the Ph.D. degree in agricultural remote sensing and information application technology from Zhejiang University, Hangzhou, China.

He is currently an Associate Professor with the Institute of Remote Sensing and Digital Earth, Chinese Academy of Sciences, Beijing, China. His research interests include vegetation remote sensing and inand vegetation ecosystem. teractions between climate change, human activities,

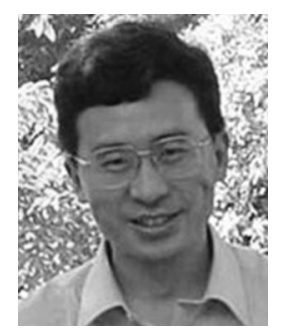

Qiming Qin received the Ph.D. degree from the Department of City and Environment Science, Peking University, Beijing, China, in 1990.

$\mathrm{He}$ is currently a Professor with the Institute of Remote Sensing \& GIS, Peking University. His research interests include quantitative remote sensing and intelligent interpretation of remote sensing images, and GIS modeling and application.

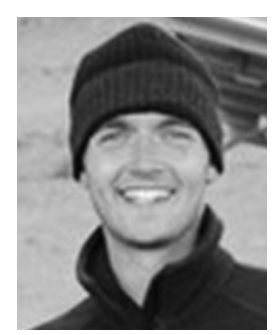

Hugh Mortimer received the Ph.D. degree in space science instrumentation from the University of Oxford, Oxford, U.K., in 2008.

He is currently with the Rutherford Appleton Laboratory, Didcot, U.K. The purpose of his research is to develop instruments that can tell us information about the atmospheres of planets. This work produces equipment to allow us to investigate, for example, the composition, temperature, and pressures of the atmospheres of earth, the planets in our solar system, and those orbiting stars far far away.

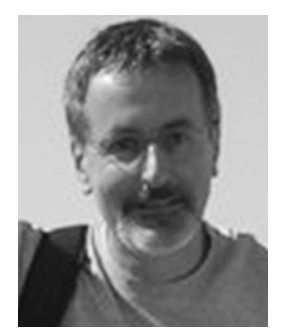

Raffaele Casa received the Ph.D. degree from the University of Dundee, Scotland, U.K., in 2003.

$\mathrm{He}$ is an Associate Professor in agronomy and experimental methods in agriculture with the University of Tuscia, Viterbo, Italy. Since more than 15 years his research has focused on the application of remote sensing and precision agriculture for the improvement of the agronomic management of crops.

Dr. Casa has been a member of the Mission Advisory Board of the Sentinel-2 Mission of the European Space Agency and is now a member of the Earth Observation Scientific Advisory Committee of the Italian Space Agency. As a member of the Group of Experts on precision agriculture with the Italian Ministry of Agriculture (2015-2016), he has coauthored the policy document on the National Guidelines for Precision Agriculture in Italy. He is a member of the Directive Committee of the Italian Society of Agronomy 2016-2017.

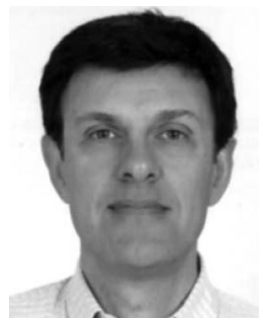

Stefano Pignatti has been a Researcher with the National Research Council, Italy, since 1995. Since 2001, he has been a Confirmed Researcher with the Institute of Methodologies for Environmental Analysis (CNR IMAA), Rome, Italy. His research interests include hyperspectral remote sensing both from airborne (VSWIR and TIR) and satellite platforms. His current activity deals with data calibration as well as the exploitation of hyperspectral remote sensing in environmental applications, including agricultural issues.

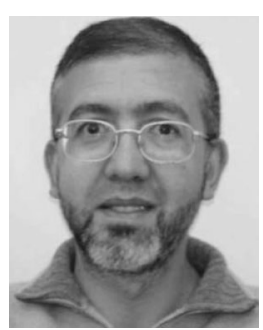

Giovanni Laneve was born in Viggiano, Italy, in 1960. He received the Laurea degree in aeronautic engineering from the Università di Napoli, Naples, Italy, in 1985, and the Laurea degree in aerospace engineering from the Università di Roma "La Sapienza," Rome, Italy, in 1988.

He has authored more than 120 scientific papers. His research interests include aeronomy, satellite thermal control, mission design, new algorithms for the exploitation of satellite images, satellite remote sensing applications for fire management, applications of satellite data for the African regions, and studies on environmental and disaster monitoring.

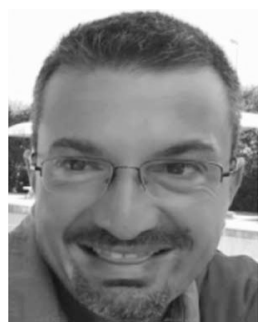

Simone Pascucci received the B.S. degree in environmental sciences from the Faculty of Environmental Sciences of the University of La Tuscia, Viterbo, Italy, in 2009.

Since 2002, he has been working on multi and hyperspectral remote sensing with the National Research Council of Italy, Rome, Italy. He has authored more than 50 articles in international journals and conference proceedings regarding applications of hyperspectral remote sensing from aircraft (MIVIS and CASI) and satellite (Hyperion, CHRIS) within the geological, urban, marine, forestry, and for the detection and estimation of materials, soil properties, and pollutants.

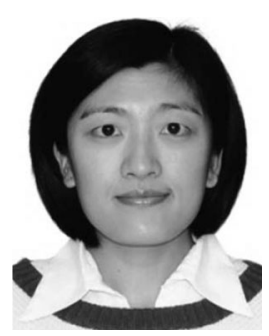

Yingying Dong received the Ph.D. degree in agricultural remote sensing and information technology from Zhejiang University, Zhejiang, China, in 2013.

She currently works with the Institute of Remote Sensing and Digital Earth, Chinese Academy of Sciences, Beijing, China. Her research interests include research and application in vegetation remote sensing.

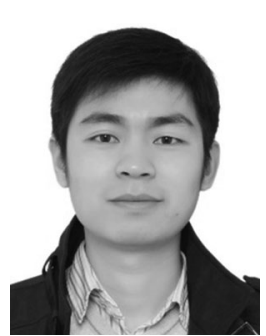

Huichun Ye received the Ph.D. degree in soil science from China Agricultural University, Beijing, China, in 2014.

He currently works with the Institute of Remote Sensing and Digital Earth, Chinese Academy of Sciences, Beijing. His current research interests include quantitative remote sensing application in vegetation monitoring and precision agriculture. 